\title{
Estudo de Análise de Combustíveis Seguindo o Padrão Exigido pela Agência Nacional do Petróleo
}

\author{
Jonathan G. Gomes, Marcos V. A. Oliveira, Márcio J. Dias, Rosemberg F. N. \\ Rodrigues, Lorena F. S. Oliveira, Vítor S. Menezes \& Eduardo C. M. Faria
}

O objetivo deste trabalho foi analisar a composição do etanol hidratado, gasolina $\mathrm{C}$ e óleo diesel S-500 em um posto da cidade de Anápolis-GO, utilizando como parâmetro normas técnicas e resolução de $n^{\circ} 9$ da ANP. Para tanto, foram coletadas 4 amostras de cada um dos combustíveis em estudo. A partir das análises realizadas, foram comparados os valores médios encontrados com os índices permitidos pela ANP, e pôde ser comprovado que nenhum dos combustíveis analisados estavam fora das especificações permitidas para comercialização. Logo, conclui-se que o posto estudado está fora das estatísticas goianas de irregularidades na comercialização de combustíveis, e que os combustíveis são de boa qualidade, não prejudicando o desempenho na queima desses combustíveis pelos automóveis.

Palavras-chaves: análise; combustiveis; qualidades.

The objective of this work was to analyze the composition of hydrous ethanol, gasoline C and diesel oil S-500 in one of the city of Anápolis-GO, using as technical parameters parameter and resolution number 9 of the ANP. For this, 4 samples of each of the fuels under study were collected. From the analyzes performed, the average values found were compared with the rates allowed by the ANP, and it can be verified that none of the analyzed fuels were outside the specifications allowed for commercialization. Therefore, it is concluded that the station studied is outside the statistics of irregularities in fuel sales, and that fuels are of good quality and do not affect the performance of these fuels by automobiles.

Key-words: analysis; fuels; quality. 


\section{Introdução}

As propriedades físico-químicas dos combustíveis podem ser alteradas com a adição de um novo composto, como os solventes ou pelo excesso de outro combustível que já seja presente naturalmente, sendo possível considerar qualquer alteração na composição química do combustível como uma adulteração. De acordo com Marques, essas adulterações trazem consequências, como: aumento do consumo de combustível, agressão aos componentes do sistema de alimentação do veículo e alteração do desempenho do motor. Além disso, suas consequências chegam ao meio ambiente, com emissões de gases de combustão nocivos, como derivados de NOx e SOx, causadores de chuva ácida, e monóxido de carbono $\mathrm{CO}$, que é altamente asfixiante ${ }^{1}$.

Dessa forma, o uso de combustíveis adulterados traz inúmeras consequências, podendo provocar um mau funcionamento dos motores e o aumento no consumo com possíveis danos ao sistema de alimentação do veículo, resultando em gastos para o proprietário.

Não somente para os veículos e seus donos existem consequências, mas também para os postos revendedores de combustíveis, onde as penalidades estipuladas pelo órgão fiscalizador Agência Nacional de Petróleo (ANP) variam desde interdição de bicos e tanques até multas severas que se alteram de acordo com as normas de cada município. ${ }^{2}$

No entanto, noticiários apontam,com grande frequência, aumento da má qualidade dos combustíveis comercializados no Brasil, devido a adulterações, mesmo com as intensas fiscalizações realizadas pela ANP. Esses dados causam preocupação à ANP, pois estas não conformidades nos combustíveis podem causar danos e falhas aos motores dos veículos, prejudicando o desempenho do automóvel e onerando o consumidor. ${ }^{3,4}$

Pode-se dizer que o monitoramento da qualidade dos combustíveis é uma forma de cumprir uma função precípua da administraça oública-defesa dos interesses da coletividade - por meio da proteção dos direitos do consumidor e dos interesses da sociedade no que se refere à oferta de combustíveis que atendam às exigências técnicas e ambientais (LIMA, 2012, p.9).
Para identificar possíveis combustíveis adulterados no Brasil, a ANP criou, em 1998, o Programa de Monitoramento da Qualidade dos Combustíveis (PMQC), sendo este programa uma ferramenta grande importância no controle da qualidade dos combustíveis comercializados no território nacional, programa que colabora para a redução dos índices de não conformidade dos produtos comercializados. ${ }^{5}$

Mesmo com os esforços do órgão que controla os combustíveis no Brasil, ainda existem muitos índices de não conformidade. Em Goiás, no segundo semestre de 2016, uma fiscalização do Programa de Proteção e Defesa do Consumidor (PROCON), em conjunto com a ANP, recolheu 80 amostras dos combustíveis: óleo diesel, etanol e gasolina $\mathrm{C}$, sendo que dentre estas, em 13 amostras foram encontradas não conformidades, ou seja, 16,25\% um índice bastante preocupante. ${ }^{6}$

Diante do exposto, este trabalho objetivou o estudo de análise de combustível, seguindo o padrão exigido pela ANP. Em seguida, foi feita uma comparação dos resultados com tabelas de níveis permitidos de acordo com a resolução ANP $n^{\circ}$ 9, verificando se os combustíveis comercializados no posto onde foram recolhidas as amostras estão ou não em conformidade com as normas da ANP.

\section{Referencial Teórico}

Atualmente, no Brasil, os principais combustíveis comercializados em postos de combustíveis são: diesel s-500, etanol, e gasolina C, sendo que os dois primeiros são derivados do petróleo e obtidos por meio do refino dele, onde a gasolina é o derivado de maior importância econômica não só no Brasil, mas no mundo. Já o etanol é produzido a partir da fermentação de açúcares, em que a matéria-prima de maior utilização é a cana-de-açúcar. Assim, o álcool é utilizado de duas formas: etanol anidro, que é um componente de mistura para a formação da gasolina $\mathrm{C}$ na proporção de $27 \%$ de álcool em $73 \%$ de gasolina $\mathrm{A}$; e etanol hidratado, que é um combustível acabado de grande utilização. ${ }^{7,8,9}$ 
Existem dois tipos de gasolinas: a de tipo A, que é agasolina pura, produzida em refinaria ou petroquímica que não é comercializada em postos de combustíveis no Brasil. O outro tipo de gasolina é a $\mathrm{C}$, comercializada em postos de combustíveis, é uma mistura da gasolina A com mais $27 \%$ de etanol anidro. ${ }^{10}$

Em relação ao óleo diesel, existem dois tipos predominantes: o S-500 e o S-10. Ressalta-se que a diferença entre os dois é a quantidade de enxofre, sendo que o S-500 possui 500 ppm, ou seja, (500 partes por milhão) e o S-10 10 pm20. Ainda é importante evidenciar que o diesel utilizado nesse estudo foi o S-500.

A queima de combustíveis fósseis representa grande parte das emissões de gases do efeito estufa por meio do dióxido de carbônico $\left(\mathrm{CO}_{2}\right)$. Assim, a gasolina polui menos que o óleo diesel, devido à sua composição de hidrocarbonetos, possuindo nível mais leve de hidrogênio e carbono em relação ao segundo combustível. Evidencia-se ainda que a gasolina é formada por moléculas de menor cadeia carbônica, que fica normalmente entre 4 e 12 átomos de carbono, já o diesel contém entre 12 e 22 átomos de carbono. ${ }^{11}$

Dos três combustíveis de maior comercialização no Brasil (diesel S-500, etanol e gasolina), o etanol vem sendo considerado o que menos prejudica o meio ambiente, pois além de ser um combustível de fonte renovável, ele produz em média $25 \%$ menos de monóxido de carbono (CO), $35 \%$ menos oxido de nitrogênio (NO) quando comparado à gasolina C. Ainda segundo a Empresa Brasileira de Pesquisas Agropecuárias (EMBRAPA), o etanol emite 70\% menos dióxido de carbono que a gasolina C. Portanto, o diesel é o combustível que mais polui, correspondendo a $53 \%$ das emissões de $\mathrm{CO}_{2}$, além de possuir alta concentração de enxofre. ${ }^{11,12}$

Apesar de o etanol hidratado emitir menor quantidade de gases de efeito estufa, sua produção traz diversos impactos ambientais, como: redução da biodiversidade, compactação do solo, contaminação de águas e consumo intenso de óleo diesel que ocasiona a emissão de grande quantidade de gases. Outro impacto relevante, causado pelo etanol, sobretudo na sua produção, é o desmatamento provocado devido às grandes áreas preparadas para o cultivo da cana-de-açúcar. Diante do fato, a Companhia Nacional de Abastecimento (CONAB), em 2015, informou que a área destinada à plantação de cana-de-açúcar no Brasil foi de $8.995,5$ mil hectares causando grande desmatamento. ${ }^{13,14}$

Em pesquisa realizada pelo Sindicato Nacional da Indústria de Componentes para Veículos Automotores (SINDIPEÇAS) juntamente à Associação Brasileira da Indústria de Autopeças (ABIPEÇAS) aponta que o número da frota circulante no Brasil, em 2015, era de 42,6 milhões de veículos, evidenciando um aumento de $2,5 \%$ quando comparado ao ano de $2014^{16}$. O estudo por tipo de combustível aponta que os veículos flex, ou seja, veículos que podem utilizar tanto gasolina C como etanol hidratado são os que predominam em circulação, representando $57,2 \%$ do total da frota; em seguida, os veículos que utilizam somente a gasolina C perfazem $31,7 \%$ do total de veículos circulando, logo em seguida aparecem os veículos movidos a óleo diesel com $9,8 \%$ e, por fim, os que utilizam somente o etanol hidratado com apenas $1,2 \%$ da frota circulante no ano de 2015. ${ }^{15,16}$

A instabilidade econômica vigente em nível nacional e internacional que afeta todos os setores econômicos, consequentemente as vendas de combustíveis faz com que existam elevações constantes nos preços. Diante destas circunstâncias, os consumidores buscam por produtos com valor abaixo do praticado visando à necessidade imediata e, por vezes, consomem combustíveis de qualidade inferior que podem prejudicar o funcionamento do veículo.

Alguns postos de gasolina, com o intuito de desbancar a concorrência e obter lucros de formas fraudulentas, diminuem excessivamente o preço da gasolina realizando adulterações e misturas, despertando a desconfiança dos consumidores e da ANP. A ANP, por sua vez, destaca,em sua Resolução de $n^{\circ}$, que qualquer consumidor que se sentir lesado em relação à qualidade do combustível tem o direito de exigir o teste do combustível ao revendedor no ato do abastecimento. ${ }^{7}$ 
Conforme o site QC Veículos (2017), e a Revista Auto Esporte (2015) quando o combustível sofre algum tipo de adulteração, que pode ser adição de etanol na gasolina, adição de água no etanol ou adição de solventes na gasolina e no etanol, causa interferência diretamente na mistura ar/combustível que chega à câmara de combustão. ${ }^{19,20}$

Portanto é muito importante a utilização de combustíveis de qualidade, pois usar combustível de baixa qualidade ou adulterado pode trazer diversas danos aos veículos. Um combustível adulterado provoca um mau desempenho do motor e o aumento no consumo, além de danificar peças como: bomba de combustível, bicos injetores, velas, catalisador, sonda lambda, entre outros. Por sua vez, danos nesses componentes podem gerar gastos com a manutenção e reparo das peças danificadas. ${ }^{17}$

Para maior controle na qualidade dos combustíveis comercializados no Brasil, a ANP criou, em 1998, o Programa de Monitoramento da Qualidade dos Combustíveis (PMCQ), com abrangência em todo o território nacional, fazendo o controle por meio de análises diárias dos combustíveis. Os postos que estão comercializando combustíveis fora dos níveis de conformidades podem ser autuados e até mesmo interditados. Além disso, têm o nome exposto em uma lista disponível no site da ANP, contendo todos os postos autuados ou interditados durante cada ano. ${ }^{3,5}$

O PMQC é um dos maiores do mundo quando comparado a outros programas de controle de qualidade de combustíveis existentes na atualidade ${ }^{5}$. Esse programa tem como principal objetivo a identificação dos focos de não conformidade e os indicadores gerais da qualidade dos combustíveis comercializados, projeto que tem sido bastante eficaz. ${ }^{3}$

Instrumento comprovadamente eficaz no controle da qualidade dos combustiveis, o programa vem sendo decisivo para a redução sistemática dos índices de não conformidade. Graças ao PMQC, a média nacional anual de irregularidade caiu de 10,7\% em 2000, para 2,2 em 2010 (Prado Filho; 2010, p.4).
Dados obtidos na revista Qualidade dos Combustíveis no Brasil apresentam a região Centro-Oeste com as maiores incidências de não conformidades, são elas: o alto índice de etanol na gasolina tipo C, representando $65,8 \%$ das ocorrências, em seguida, o teor alcoólico inadequado do etanol, representando $48,0 \%$ das não conformidades, e por fim, o óleo diesel que teve o aspecto fora das conformidades, representando $47,7 \%$ das irregularidades.

\section{Metodologia}

Este trabalho foi desenvolvido com o intuito de averiguar a qualidade dos combustíveis comercializados em um posto de combustíveis da cidade de Anápolis - Goiás. As análises foram realizadas de acordo com os procedimentos da ANP, e os procedimentos executados de acordo com Normas Brasileiras de Regulamentação, dentre elas: NBR 7148 (Massa específica), NBR 13992 (teor de etanol anidro na gasolina) e NBR 5992 (teor alcoólico).

Para tanto, foram realizadas as análises dos três tipos de combustíveis em um posto revendedor de Anápolis-GO: óleo diesel S-500, etanol e gasolina C, sendo que para cada tipo de combustível foram recolhidas 4 amostras, totalizando 12 ao final das coletas. Foram realizadas as seguintes verificações:

Para o diesel:

- Verificação visual do aspecto e cor;

- Verificação da massa específica a $20^{\circ} \mathrm{C}$.

Para o etanol:

- Verificação visual do aspecto e cor;

- Verificação da massa específica a $20^{\circ} \mathrm{C}$;

- Verificação do teor alcoólico.

Para a gasolina:

- Verificação visual do aspecto e da cor;

- Verificação da massa específica a $20^{\circ} \mathrm{C}$;

- Verificação do teor de etanol na gasolina.

Os combustíveis analisados (diesel s-500, etanol, e gasolina C) foram coletados em um posto na cidade de Anápolis. Para tanto, coletaram-se 4 amostras em um intervalo de 15 dias entre uma e outra. Em cada coleta, foram retiradas para análise 
3 amostras, nas quais, as 3 primeiras foram destinadas para análise no dia 01/09/2017, e as 3 últimas no dia 16/10/2017.

\section{Materiais Utilizados}

- Proveta de $1000 \mathrm{ml}$, utilizada para a verificação visual do aspecto, da cor e massa específica a $20^{\circ} \mathrm{C}$, para os três tipos de combustíveis.

- Proveta de $100 \mathrm{ml}$ com tampa de vidro, usada para a determinação do percentual de etanol etílico anidro na gasolina $\mathrm{C}$.

- Termômetro com variação de $-10^{\circ} \mathrm{C}$ a $50^{\circ} \mathrm{C}$ com subdivisões de $0,2^{\circ} \mathrm{C}$ ou $0,5^{\circ} \mathrm{C}$, tal termômetro deve ser aprovado pelo Instituto Nacional de Metrologia, Qualidade e Tecnologia (INMETRO) segundo as portarias $n^{\circ} 3$ de 10/01/2002, $n^{\circ} 245$ de 17/10/2000 e de $n^{\circ} 442$ de 23/11/2011, este termômetro é utilizado para a verificação da massa específica a $20^{\circ} \mathrm{C}$ no combustível etanol.

- Termômetro tipo "I" com variação de $-10^{\circ} \mathrm{C}$ a $50^{\circ} \mathrm{C}$ com subdivisões de $0,2^{\circ} \mathrm{C}$ ou $0,5^{\circ} \mathrm{C}$, termômetro esse que deve ser aprovado pelo INMETRO segundo as portarias $n^{\circ} 71$ de 28/04/2003 e $n^{\circ} 441$ de 23/11/2011, este termômetro é utilizado na verificação da massa específica a $20^{\circ} \mathrm{C}$ nos combustíveis: diesel e gasolina.

- Densímetros de vidro graduados, de acordo com a especificação American Society for Testing and Materials ATSM E-100, aprovado pelo INMETRO segundo as portarias $\mathrm{n}^{\circ} 201$ de 21/08/2000 e $\mathrm{n}^{\circ} 288$ de 12/06/2012, com as seguintes escalas descritas de acordo com o Quadro 1:

Quadro 1. Densímetros utilizados para as análises.

\begin{tabular}{|c|c|}
\hline PRODUTO & ESCALA DE MASSA ESPECIFICA $-\mathbf{g} / \mathbf{c m} 3$ \\
\hline Gasolina & $\begin{array}{c}(0,700 \mathrm{a} 0,750 \mathrm{~g} / \mathrm{ml}) \mathrm{e}(0,750 \mathrm{a} 0,800 \mathrm{~g} / \mathrm{ml}) \\
\text { Com subdivisões de } 0,0005 \mathrm{~g} / \mathrm{ml}\end{array}$ \\
\hline Diesel & $\begin{array}{c}(0,800 \mathrm{a} 0,850 \mathrm{~g} / \mathrm{ml}) \mathrm{e}(0,850 \mathrm{a} 0,900 \mathrm{~g} / \mathrm{ml}) \\
\text { Com subdivisões de } 0,0005 \mathrm{~g} / \mathrm{ml}\end{array}$ \\
\hline Etanol & $\begin{array}{c}(0,750 \mathrm{a} 0,800 \mathrm{~g} / \mathrm{ml}) \mathrm{e}(0,800 \text { a } 0,850 \mathrm{~g} / \mathrm{ml}) \\
\text { Ou }\end{array}$ \\
& \begin{tabular}{c}
$(0,770 \mathrm{a} 0,820 \mathrm{~g} / \mathrm{ml})$ Com subdivisões de $0,0005 \mathrm{~g} / \mathrm{ml}$ \\
\hline
\end{tabular} \\
\hline
\end{tabular}

- Tabelas de conversão de massa específica a $20^{\circ} \mathrm{C}$.

- Solução aquosa de cloreto de sódio $(\mathrm{NaCl})$ a $10 \%$ $\mathrm{p} / \mathrm{v}$ (100g de sal para cada litro de água).

As análises foram feitas usando os materiais citados, sendo que, todos estavam disponíveis para o uso dentro do posto onde foram coletados os combustíveis. Todas as análises ocorreram no posto revendedor, com o auxílio do gerente que tem a responsabilidade de analisar os combustíveis comprados para revenda.

\section{Resultados e Discussões}

$\mathrm{Na}$ Tabela 1, estão apresentados os resultados encontrados nas análises referentes a aspecto, cor, massa específica a $20^{\circ} \mathrm{C}$, e a porcentagem de álcool etílico anidro presente na gasolina sendo também demonstrados os valores de tolerância de acordo com a resolução ANP de $\mathrm{n}^{\circ} 9$.

Os dados apresentados na Tabela acima permitem observar que a média para o percentual de etanol etílico anidro presente na gasolina é de $26,75 \%$. Esse valor se encontra dentro do limite permitido que é de 26 a 28 \%, com um baixo desvio padrão. Logo pode-se afirmar estatisticamente que os valores médios do percentual de adição de etanol etílico estão próximos da média. Analisando a massa especifica a $20^{\circ} \mathrm{C}$ nota-se um coeficiente de variação de $0,364 \%$ valor muito baixo, indicado assim que existe pouca dispersão entre os valores. Após análise da Tabela 1 pode-se concluir que a gasolina estava própria para o consumo.

$\mathrm{Na}$ Tabela 2, estão apresentados os resultados encontrados nas análises referentes ao aspecto, cor, massa específica a $20^{\circ} \mathrm{C}$ e teor alcoólico, bem como valores de tolerância de acordo com a resolução ANP $n^{\circ} 9$ de 07/03/2007 para o etanol.

Conforme dados apresentados na Tabela 2, a média da massa específica a $20^{\circ} \mathrm{C}$ para o etanol foi de $810 \mathrm{~kg} / \mathrm{m} 3$, sendo o limite de 802,9 a $911,2 \mathrm{~kg} / \mathrm{m} 3$, com oscilação de apenas $0,5 \%$ do coeficiente de variação - ou seja, pouca dispersão dos valores medidos. Os valores dessa variável medida apresentaram um baixo desvio padrão. Logo conclui- 
se que os valores medidos tendem a estar próximos da média. Já analisando teor alcoólico, indicador mais importante para o etanol, o valor médio encontrado foi de $93,0 \%$ que também se encontra dentro do limite permitido que é de 92,5 a $95,4 \%$, com pequenos valores de $\mathrm{CV}$ e desvio padrão o que garante pequenas dispersões de valores. Portanto, após análise da estatística descritiva dessas duas variáveis, também se pode concluir que o combustível etanol hidratado está dentro das especificações estabelecidas pela resolução da ANP.

$\mathrm{Na}$ Tabela 3, estão apresentados os resultados encontrados nas análises referentes ao aspecto, cor, massa específica a $20^{\circ} \mathrm{C}$, também apresenta os valores de tolerância de acordo com a resolução ANP n ${ }^{\circ} 9$ de 07/03/2007 para o óleo diesel.

Tabela 1. Resultados das análises da gasolina $\mathrm{C}$ e tolerâncias segundo resolução $\mathrm{ANP}$ de $\mathrm{n}^{\circ} 9$

\begin{tabular}{|c|c|c|c|c|c|c|c|c|c|}
\hline \multirow{2}{*}{ Característica } & \multicolumn{2}{|c|}{ Especificação Limite } & \multicolumn{4}{|c|}{ Resultados } & \multirow[t]{2}{*}{ Média } & \multirow{2}{*}{$\mathrm{CV}$} & \multirow{2}{*}{ DP } \\
\hline & Inferior & Superior & Am1 & Am2 & Am3 & Am4 & & & \\
\hline Aspecto & - & - & Sem/Imp. & Sem/Imp. & Sem/ Imp. & Sem/Imp. & - & - & - \\
\hline Cor & - & - & $\mathrm{AM}$ & $\mathrm{AM}$ & $\mathrm{AM}$ & $\mathrm{AM}$ & - & - & - \\
\hline $\begin{array}{c}\text { Massa Específica a } \\
20^{\circ} \mathrm{C}(\mathrm{Kg} / \mathrm{m} 3)\end{array}$ & 730,0 & 770,0 & 740,6 & 746,4 & 747,6 & 746,5 & 745,2 & $0,364 \%$ & 2,73 \\
\hline $\begin{array}{c}\% \text { de etanol etílico } \\
\text { anidro }\end{array}$ & 26,0 & 28,0 & 26,0 & 27,0 & 27,0 & 27,0 & 27,0 & $1,61 \%$ & 0,433 \\
\hline
\end{tabular}

Am1, Am2, Am3 e Am4 - Amostra 1, Amostra 2, Amostra 3 e Amostra 4 respectivamente; S/imp. - sem impurezas;; AM - amarela; CV - Coeficiente de Variação; DP - desvio padrão.

Tabela 2. Resultados das análises do combustível etanol hidratado e tolerâncias segundo resolução ANP de $n^{\circ} 9$

\begin{tabular}{|c|c|c|c|c|c|c|c|c|c|}
\hline Característica & \multicolumn{1}{|c|}{ Especificação Limite } & \multicolumn{3}{|c|}{ Resultados } & Média & CV & DP \\
\hline & Inferior & Superior & Am1 & Am2 & Am3 & Am4 & & & \\
\hline Aspecto & - & - & Sem/ Imp. & Sem/ Imp. & Sem/ Imp. & Sem/ Imp. & - & - & - \\
\hline Cor & - & - & Incolor & Incolor & Incolor & Incolor & - & - & - \\
\hline $\begin{array}{c}\text { Massa Específica a } \\
\mathbf{2 0}^{\circ} \mathbf{C} \text { (kg/m3) }\end{array}$ & 802,9 & 811,2 & 809,9 & 810,3 & 809,3 & 810,5 & 810,0 & $0,05 \%$ & 0,458 \\
\hline $\begin{array}{c}\text { Teor Alcoólico } \\
\text { INPM }^{\circ}\end{array}$ & 92,5 & 95,4 & 92,8 & 93,0 & 93,2 & 93,03 & 93,01 & $0,152 \%$ & 0,142 \\
\hline
\end{tabular}

Am1, Am2, Am3 e Am4 - Amostra 1, Amostra 2, Amostra 3 e Amostra 4 respectivamente; S/imp. - sem impurezas e CV - Coeficiente de Variação; DP desvio padrão. 
Tabela 3. Resultados das análises do combustível óleo diesel S - 500 e tolerâncias segundo resolução ANP de $\mathrm{n}^{\circ} 9$

\begin{tabular}{|c|c|c|c|c|c|c|c|c|c|}
\hline \multirow[t]{2}{*}{ Característica } & \multicolumn{2}{|c|}{ Especificação Limite } & \multicolumn{4}{|c|}{ Resultados } & \multirow[t]{2}{*}{ Média } & \multirow[t]{2}{*}{$\mathrm{CV}$} & \multirow[t]{2}{*}{ DP } \\
\hline & Inferior & Superior & Am1 & Am2 & Am3 & Am4 & & & \\
\hline Aspecto & - & - & Sem/Imp. & Sem/Imp. & Sem/Imp. & Sem/Imp. & - & - & - \\
\hline Cor & - & - & Verm. & Verm. & Verm. & Verm. & - & - & - \\
\hline $\begin{array}{c}\text { Massa Específica a } \\
20^{\circ} \mathrm{C}(\mathrm{kg} / \mathrm{m} 3)\end{array}$ & 815,0 & 865,0 & 848,80 & 852,00 & 854,30 & 858,30 & 853,35 & $0,405 \%$ & 3,46 \\
\hline
\end{tabular}

Am1, Am2, Am3 e mp4 - Amostra 1, Amostra 2, Amostra 3 e Amostra 4 respectivamente; S/imp. - sem impurezas; Verm. - Vermelho; e CV - Coeficiente de Variação; DP - desvio padrão.

Por fim, os dados da Tabela 3 apresentam os resultados das análises do combustível óleo diesel S-500. Tal combustível apresentou um aspecto límpido e/ou sem impurezas para todas as quatro amostras. Analisando a média da massa específica a $20^{\circ} \mathrm{C}$, nota-se que o valor encontrado foi de $853,3 \mathrm{~kg} / \mathrm{m} 3$, ficando assim dentro do permitido pela ANP, em que o limite estipulado é de 815,0 a 865,0 , contando também com um baixo desvio padrão indicando que dados estão próximos da média. Sendo assim, após análise estatística, pode-se concluir também que o combustível em questão encontra-se dentro das especificações estipuladas.

\section{Conclusão}

De acordo com os indicadores da ANP, 16,25\% dos postos de gasolina no segundo semestre de 2016 apresentaram não conformidades, ou seja, possíveis adulterações dos combustíveis comercializados. No entanto, para as 12 coletas de combustíveis em estudo no posto coletado, sendo 4 de cada tipo (diesel s-500, etanol, e gasolina $\mathrm{C}$ ), todas estão dentro dos critérios exigidos pela ANP, ou seja, os combustíveis estão de acordo com os padrões especificados, logo podem ser utilizados sem nenhum dano aos veículos.

Ainda, os valores do coeficiente de variação e desvio padrão foram bastante baixos, ou seja, houve pouca dispersão em relação à média. Portanto, em trabalhos futuros sugere-se que sejam aumentadas as quantidades de amostras para que esses números possam ser mais bem evidenciados.

\section{Referências}

1. MARQUES, Samantha T. et al. O impacto do uso de combustível adulterado nos motores elétricos de corrente contínua de ímãs permanentes em eletrobombas de combustível. VII SEGeT Simpósio de Excelência em Gestão Tecnológica - 2010. Acesso em: 25 set. 2018

2. Agência Nacional do Petróleo, Gás Natural e Biocombustíveis: Cartilha do posto revendedor de combustíveis. - 6 ed. - Rio de Janeiro: ANP, 2017. 22 p.; il.

3. Prado Filho, H. R. Qualidade dos combustíveis no Brasil. 2010. Disponível em: <https:/qualidadeonline.wordpress.com/2010/03/03/ qualidade-dos-combustiveis-no-brasil/>. Acesso em: 28 mar. 2017.

4. Reis, B. Como você pode verificar a qualidade dos combustíveis? Disponível em: $<$ http://www.cempeqc.iq.unesp.br/como-voce-podeverificar-a-qualidade-dos-combustiveis/>. Acesso em: 28 mar. 2017.

5. Lima, A. S. Séries Temáticas ANP: O programa de monitoramento da qualidade dos combustíveis - PMCQC. 5. Ed . Rio de Janeiro: Anp, 2012. 52 p.

6. G1. Análise aponta adulteração nos combustíveis de 8 postos em Goiás. 2017. Disponível em: <http://g1.globo.com/goias/ noticia/2017/01/analise-aponta-adulteracao-nos-combustiveis-de-8postos-em-goias.html >. Acesso em: 30 mar. 2017.

7. Fogaça, J. R. V. Combustíveis Fósseis. Disponível em: <http:// mundoeducacao.bol.uol.com.br/quimica/combustiveis-fosseis.htm>. Acesso em: 10 abr. 2017.

8. Ministério Do Meio Ambiente. Combustíveis fósseis são maiores responsáveis pelo efeito estufa. Disponível em: $<$ http://www.mma. gov.br/informma/item/4125-combustiveis-fosseis-sao-maioresresponsaveis-pelo-efeito-estufa $>$. Acesso em: 10 abr. 2017. 
9. Agência Nacional do Petróleo Gás Natural e Biocombustíveis. Etanol. Disponível em: < http://www.anp.gov.br/wwwanp/ biocombustiveis/etanol>. Acesso em: 10 abr. 2017.

10. Lobo, M. T. G.Tudo sobre gasolina. 2002. Disponível em: $<$ http:// www.grupocultivar.com.br/artigos/tudo-sobre-gasolina $>$. Acesso em: 17 abr. 2017

11. Souza, L. A. Álcool, Gasolina ou Diesel: qual é o maior poluente? Disponível em: $<$ http://mundoeducacao.bol.uol.com.br/quimica/ alcool-gasolina-ou-diesel-qual-maior-poluente.htm>. Acesso em: 14 abr. 2017.

12. Rural, G. (Ed.). Etanol de cana emite $70 \%$ menos gás carbônico que gasolina, segundo Embrapa.2015.Disponível em: <http://revistagloborural.globo.com/GloboRural/0,6993,E EC1698339-1934,00.html>. Acesso em: 10 abr. 2017.

13. Companhia Nacional de Abastecimento. Acompanhamento da safra Brasileira cana-de-açúcar. Disponível em: <http://www.conab.gov. br/OlalaCMS/uploads/arquivos/15_12_17_09_03_29_boletim_cana portugues_-_3o_lev_-_15-16.pdf Acesso em: 20 abr. 2017.

14. Ramos, N. P.; Luchiari Junior, Ariovaldo. Árvore do Conhecimento Cana-de-Açucar: Impactos ecológicos. Disponível em: $<$ http://www. agencia.cnptia.embrapa.br/gestor/cana-de-acucar/arvore/CONT1. html>. Acesso em: 20 abr. 2017.

15. Automotive Business. Frota circulante no Brasil cresceu 2,5\%. 2016. Disponível em: $<$ http://www.automotivebusiness.com.br/ noticia/23905/frota-circulante-no-brasil-cresceu-25> Acesso em: 13 abr. 2017.

16. Sindipeças; Abipeças. Relatório da frota circulante de 2016. Disponível em: $<\mathrm{http}: / /$ www.sindipecas.org.br/sindinews/ Economia/2016/RFC_2016.pdf>.Acesso em: 13 abr. 2017.

17. G1. Abastecer com gasolina adulterada pode causar danos ao veículo. 2014. Disponível em: <http://g1.globo.com/sao-paulo/ itapetininga-regiao/noticia/2014/06/abastecer-com-gasolinaadulterada-pode-causar-danos-ao-veiculo.html>. Acesso em: 13 abr. 2017.

18. Falco, J. G. Estatística aplicada / Javert Guimarães Falco. Cuiabá: EdUFMT; Curitiba: UFPR, 2008.

19. Veículos, Qc. Riscos de usar combustível adulterado. Disponível em: $<\mathrm{http} / /$ qcveiculos.com.br/riscos-combustivel-adulterado/>. Acesso em: 13 abr. 2017.

20. Esporte, Auto (Ed.). Gasolina adulterada traz prejuízos ao motor e aumento do consumo;. 2015. Disponível em: <http://g1.globo.com/ carros/especial-publicitario/shell/mitos-e-verdades-do-combustivel/ noticia/2015/03/gasolina-adulterada-traz-prejuizos-ao-motor-eaumento-do-consumo-entenda.html>. Acesso em: 13 abr. 2017.

21. Petrobrás. Óleo diesel. Disponível em: $<\mathrm{http}: / /$ www.petrobras. com.br/pt/produtos-e-servicos/produtos/automotivos/oleo-diesel/>. Acesso em: 20 abr. 2017.

22. Associação Brasileira de normas Técnicas. NBR 5992: Etanol combustível - Determinação da massa específica e do teor alcoólico por densímetro de vidro. Rio de Janeiro, p. 6. 2016.
23. Associação Brasileira de Normas Técnicas. NBR 13992: Gasolina Automotiva- Determinação do teor de etanol anidro combustível (EAC). Rio de Janeiro, p.5. 2015.

24. Associação Brasileira de Normas Técnicas. NBR 7148: Petróleo e derivados de petróleo - Determinação da massa específica, densidade relativa e ${ }^{\circ} \mathrm{API}$ - Método do densímetro. Rio de Janeiro, p.11. 2013.

25. Agência Nacional do Petróleo, Gás Natural e Biocombustíveis. Resolução $n^{\circ}$ 9: Estabelece o regulamento técnico que trata do controle da qualidade do combustível automotivo líquido adquirido pelo revendedor varejista para comercialização. Rio de Janeiro. 2007.

\section{Jonathan G. Gomes*, Marcos V. A. Oliveira' ${ }^{\prime}$, Márcio J. Dias', Rosemberg F. N. Rodrigues', Lorena F. S. Oliveira'2, Vítor S. Menezes ${ }^{2} \&$ Eduardo C. M. Faria ${ }^{3}$}

\author{
${ }^{1}$ Centro Universitário de Anápolis - \\ UniEVANGÉLICA, Av. Universitária, Km 3,5, Cidade \\ Universitária, CEP 75083-515, Anápolis-GO. \\ ${ }^{2}$ Faculdade de Tecnologia SENAI Roberto Mange, \\ Rua Prof. Roberto Mange, No 152, CEP 75113-630, \\ Anápolis (GO). \\ ${ }^{3}$ Ciências Exatas \& Tecnológicas, UEG. BR 153, Km \\ 98, CEP 75133-050, Anápolis, GO.
}

\section{*E-mail: jonathan-21-@hotmail.com}

